\title{
Plasmodial sugar transporters as anti-malarial drug targets and comparisons with other protozoa
}

\author{
Ksenija Slavic ${ }^{1,2^{*}}$, Sanjeev Krishna ${ }^{1}$, Elvira T Derbyshire ${ }^{1}$ and Henry M Staines ${ }^{1}$
}

\begin{abstract}
Glucose is the primary source of energy and a key substrate for most cells. Inhibition of cellular glucose uptake (the first step in its utilization) has, therefore, received attention as a potential therapeutic strategy to treat various unrelated diseases including malaria and cancers. For malaria, blood forms of parasites rely almost entirely on glycolysis for energy production and, without energy stores, they are dependent on the constant uptake of glucose. Plasmodium falciparum is the most dangerous human malarial parasite and its hexose transporter has been identified as being the major glucose transporter. In this review, recent progress regarding the validation and development of the $P$. falciparum hexose transporter as a drug target is described, highlighting the importance of robust target validation through both chemical and genetic methods. Therapeutic targeting potential of hexose transporters of other protozoan pathogens is also reviewed and discussed.
\end{abstract}

\section{Background - Malaria burden and drug resistance} Today drug-resistant malaria is a persistent global health threat, resulting in an estimated one million human deaths worldwide. Of all malarial species, infection with Plasmodium falciparum is the cause of the greatest death toll, hitting sub-Saharan Africa hardest. Following the emergence of chloroquine resistance more than half a century ago, new drugs were introduced as alternative treatment regimens. The efficacy of these drugs deteriorated quickly, for some of them at an alarming rate, as malarial parasites evolved multiple mechanisms of drug resistance. For example, the first reports of sulphadoxine-pyrimethamine and atovaquone resistance arrived in the same year as their introduction [1]. With worsening resistance to all available anti-malarials in Southeast Asia, artemisinins, extracted from a plant used in traditional Chinese medicine for over two millennia, found worldwide application. Artemisinins are highly potent and safe anti-malarials, which are effective against multidrug-resistant P. falciparum [2-5].

One of the major goals identified to control malaria has been to prolong the lifespan of existing drugs by using drug-combination treatments. Artemisinin-based combination therapy (ACT) today includes artesunatemefloquine, artemether-lumefantrine, artesunateamodiaquine, artesunate-sulphadoxine-pyrimethamine and dihydroartemisinin-piperaquine [6]. ACT is currently recommended by WHO as the first-line treatment for uncomplicated malaria whereas recommendations for the treatment of severe malaria include artesunate or quinine given parenterally, followed by a course of an ACT [6]. Given the essential role of artemisinins in anti-malarial treatment, it is of great concern that resistance to artemisinins has recently emerged at the Thai-Cambodian border region [7-9]. While immediate action is necessary to conquer the spread of artemisinin resistance, the development of new tools to tackle malaria is even more urgent. The availability of the complete $P$. falciparum genome has facilitated identification of a series of novel candidate targets. This includes a large number of solute transport proteins that are underexploited as potential anti-malarial targets [10]. Here we describe recent advances in the development of the P. falciparum hexose transporter, PfHT, as a novel drug target.

\footnotetext{
* Correspondence: kslavic@sgul.ac.uk

${ }^{1}$ Centre for Infection, Division of Cellular and Molecular Medicine, St.

George's, University of London, Cranmer Terrace, London SW17 ORE, UK

Full list of author information is available at the end of the article
}

(c) 2011 Slavic et al; licensee BioMed Central Ltd. This is an Open Access article distributed under the terms of the Creative Commons Attribution License (http://creativecommons.org/licenses/by/2.0), which permits unrestricted use, distribution, and reproduction in any medium, provided the original work is properly cited. 
A novel approach to kill the malarial parasite - inhibition of sugar uptake

Blood is a steady and abundant source of glucose $(\sim 5$ $\mathrm{mM}$ mean level) for malarial parasites residing and multiplying inside erythrocytes. Thus, it is not surprising that blood stages of malarial parasites are dependant on glucose as their main energy source. In line with this assumption, when malarial parasites are deprived of glucose, their intracellular ATP levels drop quickly along with their cytoplasmic $\mathrm{pH}$ [11]. Glucose deprivation also causes depolarization of the parasite plasma membrane [12]. The main source of ATP production in asexual blood stages of malarial parasites is glycolysis, which is followed by anaerobic fermentation of pyruvate to lactate. Although less efficient when compared with cellular respiration, glycolysis provides fast ATP production, which is required for the rapidly replicating intraerythrocytic parasite. The rate of ATP production by anaerobic glycolysis can be up to 100 times faster than that of oxidative phosphorylation. The role of the tricarboxylic acid (TCA) cycle in Plasmodium has long been a matter of debate. Recently, it has been discovered that, at least during their asexual blood stages, malarial parasites have atypical, branched TCA metabolism, which is largely disconnected from glycolysis and therefore plays a minor role in energy metabolism [13].

Glucose from blood is delivered to the intraerythocytic malarial parasite by sugar transporters present in the host and the parasite plasma membranes. Glucose is first transported from blood plasma into the erythrocyte cytosol by GLUT1, the facilitative glucose transporter highly abundant in the erythrocyte plasma membrane. Facilitative transporters, such as GLUT1, are passive carriers that move solutes down their concentration gradients [14]. As the malarial parasite resides inside the erythrocyte surrounded by an additional membrane, the parasitophorous vacuole (PV) membrane, glucose molecules must pass this membrane before reaching the parasite surface. The parasitophorous vacuole membrane is highly permeable to glucose and other solutes with molecular weights up to $1400 \mathrm{Da}$ and these molecules pass freely between erythrocyte cytoplasm and the vacuolar space through high-capacity, low selectivity channels $[15,16]$. Finally, glucose uptake into the parasite is mediated by a facilitative transport process [17]. In the case of P. falciparum, PfHT (PlasmoDB accession number: PFB0210c) is the principal hexose transporter expressed in the parasite plasma membrane (Figure 1A) [18].

PfHT was first identified in the P. falciparum genome as a putative transporter gene showing homology to the major mammalian glucose transporter, GLUT1. Similar to GLUT1, the predicted topology of PfHT comprises
12 transmembrane helices with the amino and carboxy terminals located on the cytoplasmic side of the membrane (Figure 1B). Expression of PfHT in Xenopus laevis oocytes, enabled its detailed functional characterization. PfHT is a sodium-independent, saturable, facilitative hexose transporter [18]. While PfHT shares some of the typical sugar transporter features with the major mammalian glucose transporter, GLUT1, important mechanistic differences in their interaction with substrates have been identified. GLUT1 is selective for D-glucose $\left(K_{\mathrm{m}}=2.4 \mathrm{mM}\right)$, whereas PfHT can transport both D-glucose $\left(K_{\mathrm{m}}=1 \mathrm{mM}\right)$ and D-fructose $\left(K_{\mathrm{m}}=\right.$ $11.5 \mathrm{mM}$ ) (see Table 1). Fructose can replace glucose as an energy source when $P$. falciparum parasites are cultured in vitro [19]. Fructose gains entry to the red blood cell through the action of GLUT5, a facilitative fructose transporter present in the erythrocyte plasma membrane (Figure 1A) [20]. Uptake and metabolism of fructose probably do not play a significant physiological role for malarial parasite asexual blood stages, as plasma fructose concentrations are much lower than those of glucose, but may be important during parasite development inside the mosquito vector.

Mutational analyses of $\mathrm{PfHT}$, together with studies using a variety of hexose analogues, were performed to investigate ligand-transporter interactions. Mechanistic differences that were observed between GLUT1 and $\mathrm{PfHT}$ in terms of their interaction with substrates, suggested that selective inhibition of PfHT may be possible. Several other features of PfHT favour it as a novel drug target. Most notably, pfht is a single copy gene without a close paralogue. The $P$. falciparum genome encodes three other proteins, PFI0955 w, PFI0785 c and PFE1455 w (PlasmoDB accession numbers) that have been annotated with putative sugar transport function, but they show considerably diverged amino acid sequences compared with that of PfHT $(\leq 21 \%$ amino acid sequence identity) $[21,22]$. These putative transporters have not been investigated so far, thus their functions and cellular localizations remain unknown. Based on our genetic studies of PfHT (described later in this review), PFI0955 w, PFI0785 c or PFE1455 w do not function as alternative mechanisms for the delivery of hexoses as energy substrates for asexual blood stages of $P$. falciparum. Lack of functional redundancy is an important feature when potential drug targets are evaluated and prioritized. Also, a finding that there are no polymorphisms in PfHT amino acid sequence in eight laboratory and more than 20 field isolates analysed, adds value to PfHT as a drug target [23].

In addition to recognized therapeutic potential of PfHT, transporters that link glycolysis to apicoplast anabolism in malarial parasites may also become interesting as drug targets. The apicoplast is a relict plastid 


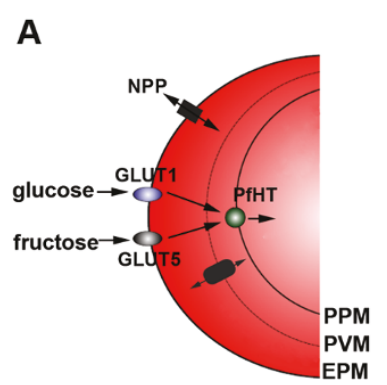

B

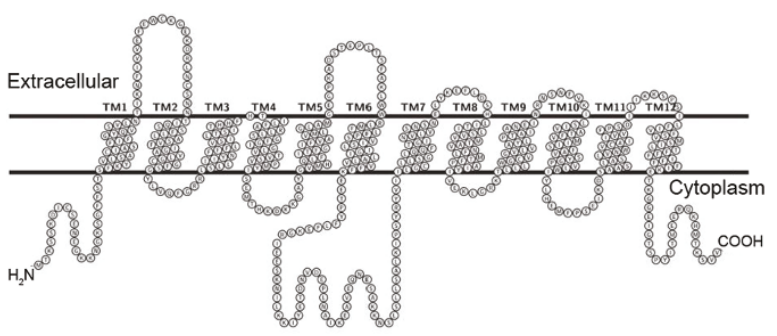

Figure 1 Schematic representation of transport processes involved in uptake of hexoses in Plasmodium-infected erythrocytes (A) and predicted topology of PfHT (B). EPM, erythrocyte plasma membrane; PVM, parasitophorous vacuole membrane; PPM, parasite plasma membrane; GLUT1, mammalian glucose transporter; GLUT5, mammalian fructose transporter; NPP, new permeability pathways (do not contribute significantly to the uptake of glucose [62]). B. Predicted topology of PfHT [18].

Table 1 Comparison of biochemical and kinetic properties of protozoan and mammalian hexose transporters

\begin{tabular}{|c|c|c|c|c|c|c|}
\hline & \multirow{2}{*}{$\begin{array}{c}\text { Properties of hexose } \\
\text { transport in parasites or } \\
\text { host membranes } \\
\mathrm{K}_{\mathrm{m}} \text { for D-glucose or 2- } \\
\text { DOG (mM) }\end{array}$} & \multicolumn{2}{|c|}{$\begin{array}{c}\text { Characterization of hexose } \\
\text { transporters genes in } \\
\text { heterologous systems } \\
\text { (Xenopus oocytes, CHO } \\
\text { cells, } \Delta / m g t \text { ) }\end{array}$} & \multirow[t]{2}{*}{$\begin{array}{l}\text { Inhibition by } \\
\text { compound } \\
3361 \mathrm{~K}_{\mathrm{i}}(\mathrm{mM})\end{array}$} & \multirow[t]{2}{*}{$\begin{array}{l}\text { Inhibition of glucose uptake by } \\
\text { D-glucose analogues: important } \\
\text { carbon position }\end{array}$} & \multirow[t]{2}{*}{ Refs } \\
\hline & & $\begin{array}{c}K_{m} \text { for } \mathrm{D}- \\
\text { glucose or 2- } \\
\text { DOG (mM) }\end{array}$ & $\begin{array}{c}\text { Transport of } \\
\text { D-fructose/ } \\
K_{m}(m M) \\
\end{array}$ & & & \\
\hline $\begin{array}{l}\text { P. falciparum } \\
(\mathrm{PfHT})\end{array}$ & $\sim 5 \mathrm{mM}$ (6-DOG) & $0.97 \pm 0.34$ & $+/ 11.6$ & $0.053 \pm 0.02$ & $1,3,6$ & {$[18,30]$} \\
\hline P. knowlesi (PkHT1) & ND & $0.67 \pm 0.16$ & $+/ 5.12$ & $0.108 \pm 0.051$ & $3,4,6$ & {$[30,63]$} \\
\hline $\begin{array}{l}\text { P. vivax } \\
\text { (PvHT) }\end{array}$ & ND & $0.52-0.85$ & $+/ 5.91-19.03$ & $0.112 \pm 0.13$ & $3,4,6$ & {$[30,63]$} \\
\hline $\begin{array}{l}\text { P. yoelii } \\
\text { (PyHT1) }\end{array}$ & ND & $0.12 \pm 0.04$ & $+/ 2.94$ & $0.080 \pm 0.016$ & $3,4,6$ & {$[30,63]$} \\
\hline $\begin{array}{c}\text { P. berghei } \\
(\mathrm{PbHT})\end{array}$ & ND & $0.09 \pm 0.02$ & 0.54 & $\sim 0.009$ & ND & {$[40]$} \\
\hline T. gondii (TgGT1) & ND & $0.030 \pm 0.006$ & $+{ }^{\S}$ & $2.073 \pm 0.59$ & $3,4,6$ & [63] \\
\hline B. bovis (BboHT1) & ND & $0.84 \pm 0.50$ & $+/ \mathrm{ND}$ & $0.005 \pm 0.002$ & 4,6 & [58] \\
\hline Leishmania LmGT1 & $1.22 \pm 0.22$ & ND & $+/ \mathrm{ND}$ & ND & ND & {$[56]$} \\
\hline Leishmania LmGT2 & $109 \pm 22$ & ND & $+/ \mathrm{ND}$ & ND & ND & {$[56]$} \\
\hline Leishmania LmGT3 & $208 \pm 40$ & ND & $+/ \mathrm{ND}$ & ND & ND & {$[56]$} \\
\hline $\begin{array}{l}\text { T. brucei } \\
\text { THT1 }\end{array}$ & $0.5-2.0$ & ND & $+/ 2.56-3.91$ & ND & 3,4 & {$[55,64-66]$} \\
\hline $\begin{array}{l}\text { T. brucei } \\
\text { THT2 }\end{array}$ & $0.038-0.08 / 2.0$ & $0.151 \pm 0.01$ & $+/ 2.54$ & ND & $3,4,6$ & [66] \\
\hline $\begin{array}{l}\text { T. vivax } \\
\text { TvHT1 } \\
\end{array}$ & $0.585 \pm 0.068$ & $0.545 \pm 0.02$ & $+/ \mathrm{ND}$ & ND & $1,3,6$ & {$[65-67]$} \\
\hline GLUT1 & $4-10$ & $\sim 2$ & - & $3.3 \pm 0.21$ & $1,4,6$ & {$[19,66]$} \\
\hline GLUT5 & ND & - & $+/ 13$ & ND & ND & [68] \\
\hline
\end{tabular}

ND - not determined

$\S$ - D-fructose uptake at $37^{\circ} \mathrm{C}$

$+/ \mathrm{ND}$ - transport of fructose observed but $\mathrm{K}_{\mathrm{m}}$ not determined

$\Delta / m g t$ - glucose transporter null mutant of Leishmania mexicana

$\mathrm{CHO}$ - The Chinese hamster ovary $(\mathrm{CHO})$ cell line 
organelle that arose from a secondary endosymbiotic event [24]. This organelle is indispensable for parasite survival, which makes it attractive for therapeutic targeting. It contains four membranes and, therefore, requires complex transport systems. Despite being an anabolic organelle little is known about nutrient transport across its multiple membranes. Synthesis of fatty acids, isoprene precursors and haem is localized to the apicoplast and requires reduced carbon compounds and energy to be functional. The question of how these anabolic processes are fuelled in a non-photosynthetic plastid is of particular interest. Two transporters have been identified (PfiTPT (PFE1510 c) and PfoTPT (PFE0410 w)) that are localized in the innermost and outermost apicoplast membranes, respectively, and are homologous to plant transporters that move phosphorylated trioses, pentoses and hexoses across the chloroplast envelope in exchange for inorganic phosphate [25]. PfiTPT and PfoTPT have been proposed to act in tandem to transport glycolytic intermediates from the cytoplasm to the apicoplast, providing a source of carbon, reducing power and ATP required for biosynthetic processes [25]. Recently, using a cell-free transporter assay system, these two transporters have been found to show equivalent substrate preferences, with high substrate affinity for phosphoenolpyruvate and lower affinities for dihydroxyacetone phosphate and 3-phosphoglyceric acid, supporting the view that they act together to import these glycolytic intermediates into the apicoplast [26]. By being the link between cytoplasmic glycolysis and apicoplast anabolism, PfiTPT and PfoTPT are potential drug targets [25], but they require further validation steps.

\section{Genetic and chemical approaches to target validation}

Validation of a particular parasite protein as a potential drug target can be performed by chemical or genetic tools. Chemical validation requires identification of a compound that specifically inhibits the parasite protein of interest without having an effect on the orthologous host proteins. Such a selective inhibitor also needs to demonstrate parasiticidal activity in vitro and/or in vivo. In certain cases, inhibition of parasite growth in vitro occurs at inhibitor concentrations lower than those necessary to block the transporter in a heterologous expression system. Various factors can account for this inhibitory difference between the two techniques, including the level of transporter expression, environmental factors that influence ligand binding (e.g. the composition of the lipid membrane) and inhibitor accumulation mechanisms.

Genetic validation involves a genetic modification of the parasite to "knock-out" a gene and show that lossof-function of the protein results in non-viable or severely disabled parasites [27]. Also, if a specific inhibitor is available, the parasite can be genetically modified to over-express the potential target protein. In this case, demonstration of reduced inhibition with over-expression of the protein validates that protein as the molecular target of the applied drug.

Due to high target attrition rates during drug discovery projects, it is desirable that both chemical and genetic validation data are available for a novel target. Both of these methods have specific advantages but are also characterized with certain weaknesses. Chemical target validation provides information addressing the key druggability issues of cell permeability, selective toxicity and drug metabolism [28]. Also, it enables identification of non-protein targets. Genetic approaches, on the other hand, enable validation of targets with unknown function or for which highly specific inhibitors are not available. With the chemical validation approach, it is sometimes difficult to demonstrate the correlation between the target inhibition and the phenotype. Genetic validation, therefore, presents the "gold standard" for providing evidence for an essential function of a protein. Generally, the inability to obtain a chromosomal null mutant for a certain gene suggests the essential function of that gene for growth or survival but to definitely prove this, 'rescue' of the chromosomal null mutant must be achieved through expression of another copy of the gene. On the other hand, a gene knock-out that results in the growth of viable parasites suggests that the gene is not essential and probably not a drug target. It is important to note, however, that in certain circumstances it is possible to obtain viable organisms with the knock-out of an essential gene. This is possible through the occurrence of genetic changes at other loci that compensate for the lethal effect of the knock-out [28], or because in vitro conditions for growth are more permissive than those pertaining in vivo. This emphasizes the importance of both genetic and chemical validation approaches. Spontaneous amplification of an alternative transporter has, for example, been observed in a Leishmania mexicana glucose transporter null mutant (see below) [29]. Also, a gene that can be disrupted at one particular life cycle stage of a parasite may have an essential function during other life cycle stages.

\section{Chemical validation of PfHT as a drug target}

Besides enabling functional studies, an additional value of the established robust heterologous expression system of PfHT in X. laevis oocytes was the opportunity to screen a series of glucose analogues and other compounds for their inhibitory properties. In an early study and based on previous findings with hexose analogues, a library of glucose derivatives with varying chain lengths 
at the $\mathrm{C}-3$ position was generated and studied [30]. One of the compounds, 3-O-[undecyl-10-en]-1-yl-D-glucose, also known as compound 3361 (Figure 2A), was identified as an effective inhibitor of PfHT-mediated glucose transport in Xenopus oocytes as well as demonstrating a high degree of selectivity for PfHT over GLUT1 (see Table 1). The $K_{\mathrm{i}}$ value of compound 3361 on glucose uptake by PfHT was found to be $53 \mu \mathrm{M}$. Compound 3361 killed $P$. falciparum in vitro $\left(\mathrm{IC}_{50}\right.$ of $\left.15 \mu \mathrm{M}\right)$ and also showed activity in an in vivo murine model; a significant suppression of Plasmodium berghei parasitaemia was shown in a standard four-day suppression test [30]. These studies chemically validated PfHT as a novel drug target. Demonstration that compound 3361 acts via inhibition of transport rather than affecting the metabolism of glucose came from a study that measured uptake of non-metabolizable glucose analogues in P. falciparum parasites freed from erythrocytes by saponin lysis [31].

The therapeutic potential of PfHT has been further supported by findings that its orthologues in Plasmodium vivax and Plasmodium knowlesi are susceptible to inhibition by compound 3361 [32]. This compound also kills short-term cultures of $P$. vivax isolated from patients [32]. These findings suggest that if anti-malarials based on the inhibition of hexose transport are developed, they could be used for the treatment of nonfalciparum malarias as well.

Later studies, using the Xenopus expression system of $\mathrm{PfHT}$, further investigated inhibitory properties of sugar-based derivatives. A 3-O-substituted chain length of between 8-13 carbons is necessary to maintain inhibitory activity against PfHT [33]. Also, repositioning of the $O$-[undecyl-10-en]-1-yl substituent at $\mathrm{C} 2$ in the glucose molecule produced a significantly higher affinity inhibitor $\left(K_{i}\right.$ of $2 \mu \mathrm{M}$ against PfHT, see Figure $\left.2 \mathrm{~B}\right)$ compared with the $\mathrm{C} 3$ derivative, compound 3361 [34]. Similar to compound 3361, 2-O-[undecyl-10-en]-1-yl-Dglucose retained selective inhibitory activity against PfHT over GLUT1 and also inhibited P. falciparum growth in vitro [34].

PfHT can also be inhibited by compounds that do not have glucose-based structures. Recently, we have explored inhibitory potential of catechins, flavonoid
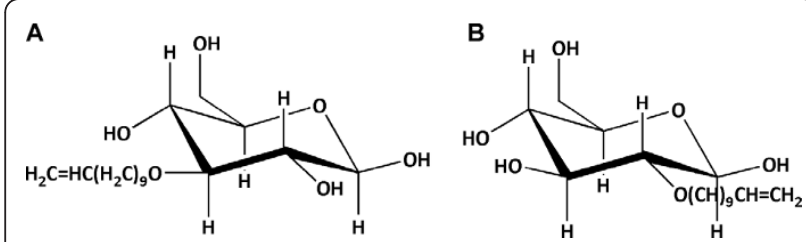

Figure 2 Structures of the glucose-derived PfHT inhibitors. A. 3O-(undec-10-en)-1-yl-D-glucose (Compound 3361); B. 2-O-(undec-10en)-1-yl-D-glucose. compounds naturally found in green tea, against parasite and mammalian hexose transporters [35]. This study was driven by findings that some catechins inhibit mammalian GLUT1 and also show anti-malarial properties [36,37]. As with GLUT1, it was found that catechins containing a gallate group (epicatechin-gallate and epigallocatechin-gallate) inhibit PfHT and mammalian GLUT5. However, although these compounds inhibited hexose uptake processes in infected erythrocytes, the primary mechanism of their anti-malarial activity probably involves interaction with alternative higher affinity target/s [35].

\section{Genetic validation of essential function of PfHT for asexual blood stages}

To add further support for PfHT as a novel drug target, $p f h t$ was investigated using genetic tools. Since the malarial parasite is haploid for a greater part of its life cycle (except for the short zygote and ookinete stages inside the mosquito midgut), reverse genetic studies of an essential gene are not straightforward, as the knockout of such a gene would have a lethal effect. Therefore, in genetic studies of $p f h t$, a knock-out/complementation system was used, which has been successfully used in research of $P$. falciparum kinases [38]. With this approach, a knock-out of a gene of interest is attempted with or without the presence of a complementation vector that allows episomal, "rescue", expression of the gene of interest. If the gene is essential, its knock-out would be lethal for the parasite and will only be achieved in the presence of a rescuing, complementation vector. In this way, it was established that $p f h t$ is essential for survival of asexual blood stages [39]. Additionally, a transgenic $P$. falciparum line overexpressing $p f h t$ is less susceptible to growth inhibition by compound 3361 compared with wild-type parasites. This transgenic line may represent a useful tool to link activities of future putative PfHT inhibitors to the target. The essential function of the hexose transporter for survival of blood stages was confirmed in a rodent malarial model, $P$. berghei. The $P$. berghei hexose transporter gene pbht (PlasmoDB accession number: PB000562.01.0), is accessible for genetic targeting, as shown by $g f p$-tagging of the gene, but is refractory to knock-out attempts [39]. Recently, this finding has been reproduced, using a similar genetic approach [40].

Therefore, PfHT has been validated as a drug target both chemically and genetically, and so far it is the only transport protein for which both validation approaches have been undertaken.

\section{Life cycle studies}

In addition to an essential function of PfHT for asexual blood stages of the malarial parasite, this transporter is 
also important for parasite development and/or survival at other stages of its complex life cycle. This has been investigated using transgenic $P$. berghei lines, amenable to in vivo life cycle studies. PbHT expression was analysed by direct imaging of live parasites expressing PbHT fused to a GFP reporter $[39,41]$ and by immunofluorescence analysis of a transgenic line expressing $\mathrm{PbHT}$ fused to the haemagglutinin epitope [40]. PbHT was constitutively expressed throughout the parasite's development inside the mosquito vector as well as during the hepatic stages (see Figure 3 for examples). This is in keeping with previous transcriptomic and proteomic studies [42-46].

Glucose transport by plasmodial hexose transporters is necessary for normal development of insect stages (microgametes, ookinetes and oocysts), as shown by inhibitory studies with compound 3361. Compound 3361 reduced the number of oocysts formed inside infected mosquito midguts, when tested using a membrane feed assay [41] as well as when mosquitoes were fed on compound 3361 treated, P. berghei-infected mice [40]. Compound 3361 also affects exflagellation of male gametes and ookinete production in a dose-dependant manner with $\mathrm{IC}_{50}$ values of between 100 to $300 \mu \mathrm{M}$ $[40,41]$, although only the former in a glucose-sensitive manner [41]. PfHT targeting thus holds some potential for transmission blocking strategies. The only current drugs that can kill P. falciparum gametocytes and, thus, reduce transmission are 8 -aminoquinolines, such as primaquine [47]. The use of primaquine is hampered by the haemolysis this drug causes in patients with glucose-6-phosphate dehydrogenase (G6PD) deficiency [48]. Artemisinins inhibit early stages of gametocyte development.

Liver stages of the malarial parasite are also killed by compound 3361 (with an $\mathrm{IC}_{50}$ of $11 \mu \mathrm{M}$ ) [40,41]. This effect was not due to reduced viability of the host hepatoma cells or to inhibition of host glucose uptake pathways [41]. These data suggest that novel chemotherapeutic interventions that target PfHT may well be active against

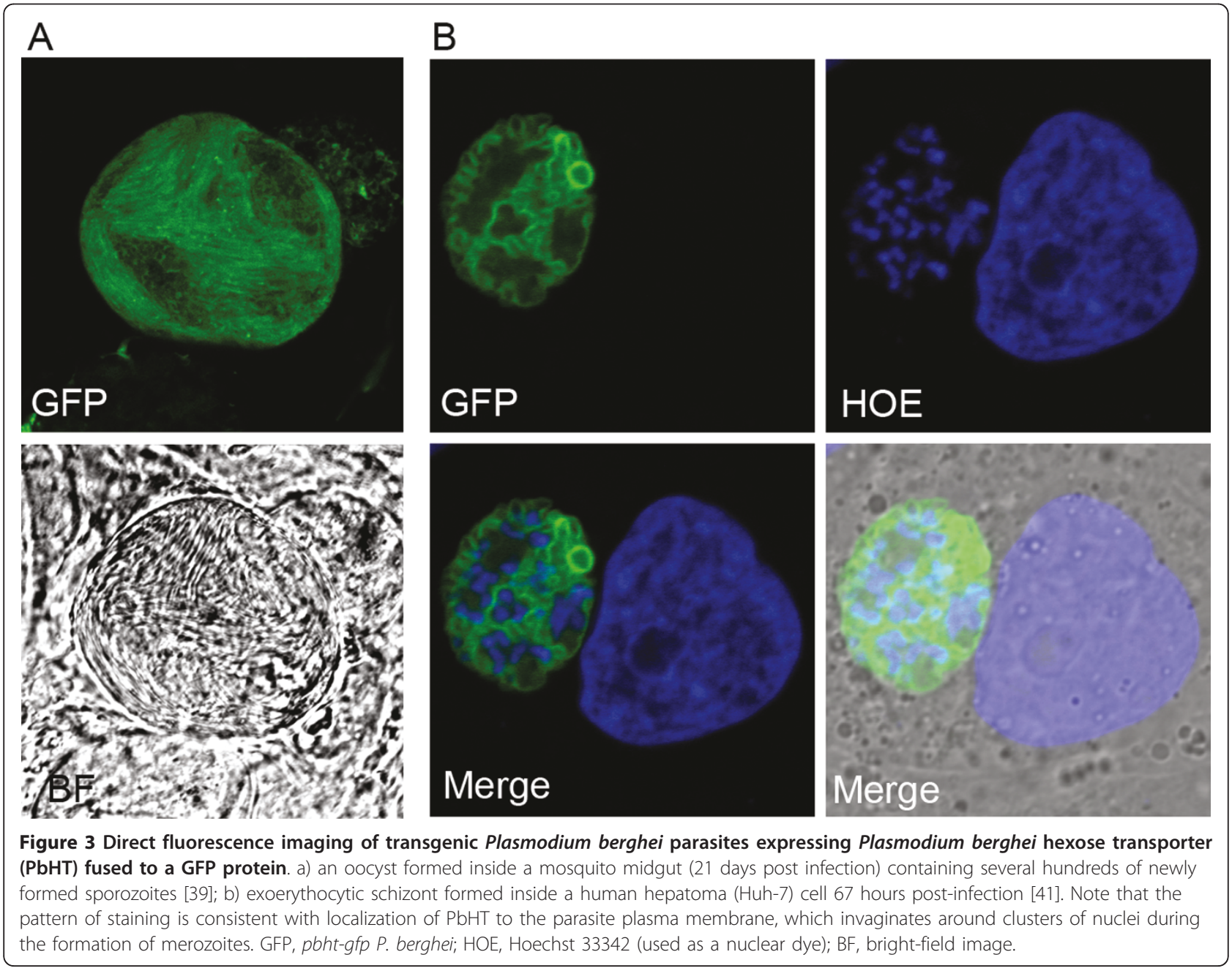


liver stages. Efficacy against malarial parasite liver stages has gained increasing attention as a desirable property of new anti-malarials [49]. Drugs that act at this stage, preventing sporozoite infection or replication of parasites in the liver, stop the infection from reaching the symptomatic blood stages. Since very limited number of drugs have this causal prophylactic activity (namely primaquine, proguanil and atovaquone), it is important to identify novel potential strategies.

\section{High throughput screening systems}

After a target has been robustly validated, the next step of its development as a drug target requires a high throughput system for the screening of compound libraries. A promising system for functional expression of parasite and human glucose transporters has recently been developed based on a glucose transporter null mutant of Leishmania mexicana, named $\Delta l m g t$ [50,51]. PfHT, T. brucei hexose transporter THT1 and human GLUT1 have been successfully expressed in $\Delta l m g t$ heterologous system. It was demonstrated that functional complementation of $\Delta l m g t$ with parasite and human transporters can be used to identify inhibitory compounds specific for parasite glucose transporters [50]. An advantage of $\Delta l m g t$ as an expression system compared with mammalian cells is the absence of background glucose uptake. This background, characteristic for mammalian cells due to the presence of multiple endogenous glucose transporters, may affect the inhibition data obtained during experiments. The $\Delta l m g t$ system is amenable to high throughput screening by using a cell-permeable dye, alamarBlue ${ }^{\mathrm{TM}}$, which is reduced by viable parasites and in its reduced form emits a strong fluorescence signal that is a quantitative measure of the parasite count [50]. Recent expression of PfHT in a yeast mutant cell line deficient in endogenous hexose transporters may potentially be useful in high-throughput studies of inhibitors [40], although this system requires further validation, including comparisons to yeast mutants expressing mammalian glucose transporters as well as development of a screening assay methodology.

Several thousand new chemical entities with in vitro activity against both sensitive and multidrug resistant $P$. falciparum were discovered recently $[52,53]$. These newly identified libraries of active compounds may serve as an excellent starting point for target-based lead discovery, which has not produced satisfactory results so far, mostly due to lack of whole-cell activity [52].

\section{Potential of glucose transporters of other pathogens as drug targets}

In addition to malarial parasites, the uptake of glucose is essential for the viability of several other protozoan pathogens. This has been established for Trypanosoma brucei, a pathogen causing sleeping sickness. Sleeping sickness is fatal if untreated and novel trypanocides are required because current treatments are not satisfactory due to a lack of efficacy, poor safety profiles, difficulties in administration and/or high cost [54]. Glycolysis has been considered a promising target for new drugs against trypanosomiasis. The reason for this, in addition to glycolysis being essential for the survival of blood stage parasites, is the unique nature of this pathway in Trypanosoma [54]. The first seven reactions of the glycolytic pathway happen inside peroxisome-like organelles called glycosomes and the enzymes involved display unique structural and kinetic properties, which are distinct from those of the mammalian host. Glucose uptake in T. brucei happens via two glucose transporters, THT1 and THT2 (Trypanosoma hexose transporter 1 and 2) (Table $1)$. The lower glucose affinity THT1 $\left(\mathrm{K}_{\mathrm{m}} \sim 1 \mathrm{mM}\right)$, is the isoform expressed in the blood stages, whereas the highaffinity THT2 $\left(\mathrm{K}_{\mathrm{m}} \sim 0.05 \mathrm{mM}\right)$ is expressed during insect stages. Glucose and fructose analogues can inhibit glucose uptake by THT1 and kill the blood forms of T. brucei [55]. THT1, therefore, may represent a good drug target and its heterologous expression, which has been achieved in the L. mexicana glucose transporter null mutant mentioned before, may facilitate the search for a specific inhibitory compound [50].

Glucose is also an essential nutrient for the infectious stages of L. mexicana, an intracellular parasite of macrophages, which causes cutaneous leishmaniasis. The uptake of glucose is essential for proliferation of diseasecausing amastigote stages of L. mexicana [56]. Glucose uptake in L. mexicana is mediated by three glucose transporter isoforms, LmGT1, LmGT2 and LmGT3 (Leishmania mexicana glucose transporter 1, 2 and 3) (Table 1) [56]. The three glucose transporter isoforms are very similar in their protein sequences but they have specific subcellular localizations and display developmentally-regulated expression [56,57]. The importance of hexose transport for infectious stages of $L$. mexicana has been further supported by a recent discovery of spontaneous suppressors of the glucose transporter null mutant, $\Delta l m g t$ [29]. These suppressor mutants have regained the ability to transport hexoses through an amplification of an alternative glucose transporter gene, the LmGT4 permease, and have also partially restored virulence [29]. Thus, although inhibition of L. mexicana glucose transporters has not been investigated (in the way it has been done for P. falciparum and T. brucei hexose transporters, using glucose analogue-based inhibitors), interference with their function may show therapeutic potential.

Babesia are tick-borne haemoprotozoan apicomlexan parasites, sharing many similarities, including their 
asexual blood-stage proliferation with Plasmodium. Babesia bovis causes severe infections in cattle and imposes a high economic burden. Babesia bovis hexose transporter 1 - BboHT1 (Table 1), one of the two hexose transporters identified in the genome of this parasite, has been expressed and characterized in Xenopus oocytes [58]. BboHT1 is approximately 10-fold more sensitive to inhibition by compound 3361 compared with PfHT but this compound does not affect parasite growth [58]. It is possible that compound 3361 may not reach the intraerythrocytic site of BboHT1 or that another D-glucose transport pathway, insensitive to compound 3361, is present [58]. Alternatively, the parasite may not rely completely on glucose as an energy source. The authors have suggested that the parasites may oxidize glutamate via glutamate dehydrogenase, which is present in blood stages, and feed the resulting $\alpha$-ketoglutarate into the tricarboxylic acid cycle [58]. Evidence obtained so far, therefore, cannot support BboHT1 as a drug target.

Toxoplasma gondii, an obligate intracellular parasite of the Apicomplexa phylum related to Plasmodium, can tolerate the deletion of its surface sugar transporter without an effect on its virulence [59]. The authors of this study have suggested that in $T$. gondii glucose metabolism is dispensable because of glutaminolysis. The ability to use alternative energy sources has probably co-evolved with the ability of these parasites to replicate in most cell types. Thus, phylogenetically closely related parasites, such as Toxoplasma, Babesia and Plasmodium, can fundamentally differ in terms of their dependence on glucose and essentiality of their glucose transporters. During their life cycles, the ability of some parasites to use alternative energy sources may depend on the specific life cycle stage. For example, insect stages of T. brucei (procyclic forms) and L. mexicana (promastigotes) can thrive in glucose-depleted medium $[60,61]$, whereas the growth of their mammalian stages is dependant on glucose (as described above).

\section{Conclusions}

Hexose transporters of the three most pathogenic malarial parasites, $P$. falciparum, $P$. vivax and $P$. knowlesi, have been validated as novel drug targets. In addition to an essential role of plasmodial hexose transporters during parasite blood stages, these transporters may also have a crucial role for liver and insect stages of malarial parasite life cycles (see Figure 4 for summary).

Glucose transport has also been found to be essential for the viability of T. brucei and L. mexicana infectious stages. Thus, inhibition of hexose transport may present

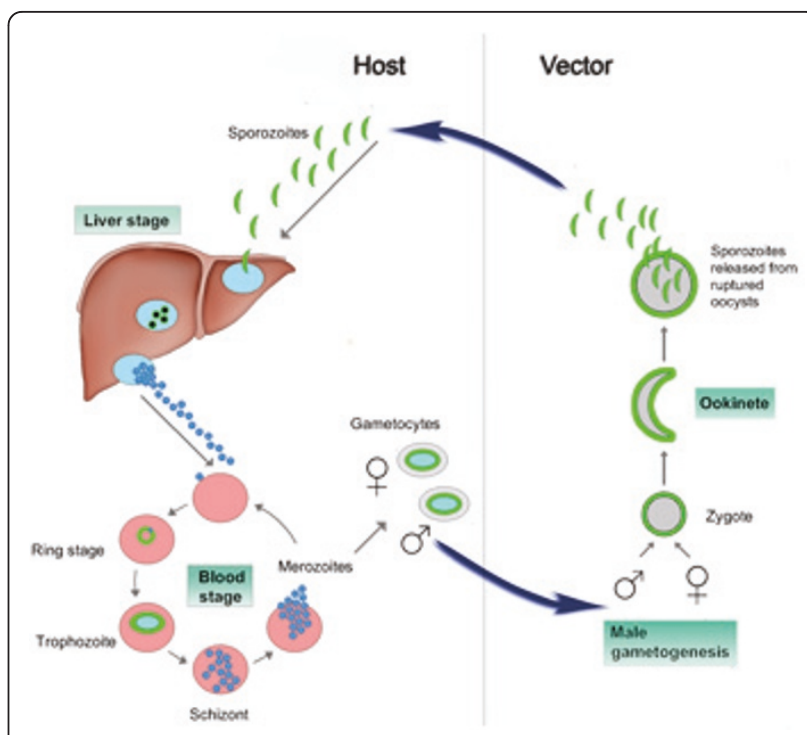

Figure 4 Schematic representation of the life cycle of Plasmodium parasites showing a summary of inhibition and expression studies of plasmodial hexose transporters. Parasites shown in green represent a pbht-gfp transgenic line, which has been analysed via direct fluorescence imaging. Using this transgenic line, expression of PbHT-GFP was observed at 24, 48 and $67 \mathrm{~h}$ post infection in the liver stage [41], in both early and late asexual blood stages, in sexual blood stage forms (gametocytes) and in female gametes/or zygotes, ookinetes, midgut oocysts and sporozoites derived from mosquito midgut oocysts and salivary glands [39]. Highlighted life cycle stages (blue boxes) show where compound 3361 inhibits parasite growth and development; in the liver stages in vitro, P. berghei parasite growth is inhibited by compound 3361 with an $\mathrm{IC}_{50}$ value of $11 \mu \mathrm{M}$ [41]; in the asexual blood stages in vitro, P. falciparum parasite growth is inhibited by compound 3361 with an $I C_{50}$ value of $16 \mu \mathrm{M}$ and in vivo $P$. berghei parasite growth is reduced by $40 \%$ (4-day suppression test; $25 \mathrm{mg} / \mathrm{kg}$; administered i.p. twice daily) [30]; in $P$. berghei sexual stages male gametogenesis $\left(\mathrm{IC}_{50}\right.$ value of $\left.286 \mu \mathrm{M}\right)$ and ookinete production $\left(\mathrm{IC}_{50}\right.$ value of 252 $\mu \mathrm{M})$ are inhibited by compound 3361 [41].

an attractive approach in the development of other new anti-parasitic drugs, in addition to the discovery of novel anti-malarials.

\section{Abbreviations}

BboHT1: Babesia bovis hexose transporter 1; GLUT1/5: mammalian facilitative glucose transporter 1/5; LmGT1/3: Leishmania mexicana glucose transporter 1/3; PfHT: Plasmodium falciparum hexose transporter; THT1/2: Trypanosoma brucei hexose transporter $1 / 2$.

\section{Acknowledgements and Funding}

This work was funded by European Commission projects ANTIMAL (Grant No. 018834) and MALSIG (Grant No. 223044) and the Wellcome Trust (Grant No. 076441). HMS is a Research Career Development Wellcome Trust Fellow.

\section{Author details}

${ }^{1}$ Centre for Infection, Division of Cellular and Molecular Medicine, St. George's, University of London, Cranmer Terrace, London SW17 ORE, UK. ${ }^{2}$ Centre for Parasitic Zoonoses, Institute for Medical Research, University of Belgrade, Dr. Subotica 4, 11129 Belgrade, Serbia. 


\section{Authors' contributions}

All authors contributed in the conception of the article; KS and HMS drafted the manuscript; ETD generated table, figures ( 1 and 4$)$ and provided text for subsections. HMS and SK critically reviewed and revised the manuscript. All authors read and approved the final manuscript.

\section{Competing interests}

The authors declare that they have no competing interests.

Received: 3 April 2011 Accepted: 15 June 2011 Published: 15 June 2011

\section{References}

1. Wongsrichanalai C, Miller RS: Malaria rapid tests: a public health perspective. Lancet 2002, 359:1781.

2. Haynes RK, Krishna S: Artemisinins: activities and actions. Microbes Infect 2004, 6:1339-1346.

3. Kremsner PG, Krishna S: Antimalarial combinations. Lancet 2004, 364:285-294.

4. Krishna S, Bustamante L, Haynes RK, Staines HM: Artemisinins: their growing importance in medicine. Trends Pharmacol Sci 2008, 29:520-527.

5. White NJ: Qinghaosu (artemisinin): the price of success. Science 2008, 320:330-334

6. WHO: World Malaria Report Geneva: WHO Press; 2008, 1-215.

7. Dondorp AM, Nosten F, Yi P, Das D, Phyo AP, Tarning J, Lwin KM, Ariey F, Hanpithakpong W, Lee SJ, Ringwald P, Silamut K, Imwong M, Chotivanich K Lim P, Herdman T, An SS, Yeung S, Singhasivanon P, Day NP, Lindegardh N, Socheat D, White NJ: Artemisinin resistance in Plasmodium falciparum malaria. N Engl I Med 2009, 361:455-467.

8. Noedl H, Se Y, Schaecher K, Smith BL, Socheat D, Fukuda MM: Evidence of artemisinin-resistant malaria in western Cambodia. N Engl J Med 2008, 359:2619-2620.

9. Noedl H, Socheat D, Satimai W: Artemisinin-resistant malaria in Asia. N Engl I Med 2009, 361:540-541.

10. Staines HM, Derbyshire ET, Slavic K, Tattersall A, Vial H, Krishna S: Exploiting the therapeutic potential of Plasmodium falciparum solute transporters. Trends Parasitol 2010, 26:284-296.

11. Saliba KJ, Kirk K: pH regulation in the intracellular malaria parasite, Plasmodium falciparum. $\mathrm{H}(+)$ extrusion via a v-type $\mathrm{h}(+)$-atpase. J Biol Chem 1999, 274:33213-33219.

12. Allen RJ, Kirk K: The membrane potential of the intraerythrocytic malaria parasite Plasmodium falciparum. J Biol Chem 2004, 279:11264-11272.

13. Olszewski KL, Mather MW, Morrisey JM, Garcia BA, Vaidya AB, Rabinowitz JD, Llinas M: Branched tricarboxylic acid metabolism in Plasmodium falciparum. Nature 2010, 466:774-778.

14. Manolescu AR, Witkowska K, Kinnaird A, Cessford T, Cheeseman C: Facilitated hexose transporters: new perspectives on form and function. Physiology (Bethesda) 2007, 22:234-240.

15. Desai SA, Krogstad DJ, McCleskey EW: A nutrient-permeable channel on the intraerythrocytic malaria parasite. Nature 1993, 362:643-646.

16. Desai SA, Rosenberg RL: Pore size of the malaria parasite's nutrient channel. Proc Natl Acad Sci USA 1997, 94:2045-2049.

17. Kirk K, Horner HA, Kirk J: Glucose uptake in Plasmodium falciparuminfected erythrocytes is an equilibrative not an active process. $\mathrm{Mol}$ Biochem Parasitol 1996, 82:195-205.

18. Woodrow CJ, Penny JI, Krishna S: Intraerythrocytic Plasmodium falciparum expresses a high affinity facilitative hexose transporter. J Biol Chem 1999, 274:7272-7277.

19. Woodrow CJ, Burchmore RJ, Krishna S: Hexose permeation pathways in Plasmodium falciparum-infected erythrocytes. Proc Natl Acad Sci USA 2000, 97:9931-9936.

20. Velasquez FV, Martinez JM, Angulo C, Droppelmann A, Reyes AM, Slebe JC, Vera JC, Golde DW: Human erythrocytes express GLUT5 and transport fructose. Blood 1997, 89:4190-4195.

21. Gardner MJ, Hall N, Fung E, White O, Berriman M, Hyman RW, Carlton JM, Pain A, Nelson KE, Bowman S, Paulsen IT, James K, Eisen JA, Rutherford K, Salzberg SL, Craig A, Kyes S, Chan MS, Nene V, Shallom SJ, Suh B, Peterson J, Angiuoli S, Pertea M, Allen J, Selengut J, Haft D, Mather MW, Vaidya AB, Martin DM, Fairlamb AH, Fraunholz MJ, Roos DS, Ralph SA, McFadden Gl, Cummings LM, Subramanian GM, Mungall C, Venter JC, Carucci DJ, Hoffman SL, Newbold C, Davis RW, Fraser CM, Barrell B:
Genome sequence of the human malaria parasite Plasmodium falciparum. Nature 2002, 419:498-511.

22. Martin RE, Henry Rl, Abbey JL, Clements JD, Kirk K: The 'permeome' of the malaria parasite: an overview of the membrane transport proteins of Plasmodium falciparum. Genome Biol 2005, 6:R26.

23. Krishna S, Eckstein-Ludwig U, Joet T, Uhlemann AC, Morin C, Webb R, Woodrow C, Kun JF, Kremsner PG: Transport processes in Plasmodium falciparum-infected erythrocytes: potential as new drug targets. Int J Parasitol 2002, 32:1567-1573.

24. Lim L, McFadden GI: The evolution, metabolism and functions of the apicoplast. Philos Trans R Soc Lond B Biol Sci 2010, 365:749-763.

25. Mullin KA, Lim L, Ralph SA, Spurck TP, Handman E, McFadden Gl: Membrane transporters in the relict plastid of malaria parasites. Proc Natl Acad Sci USA 2006, 103:9572-9577.

26. Lim L, Linka M, Mullin KA, Weber AP, McFadden Gl: The carbon and energy sources of the non-photosynthetic plastid in the malaria parasite. FEBS Lett 2010, 584:549-554.

27. Cowman AF, Crabb BS: Functional genomics: identifying drug targets for parasitic diseases. Trends Parasitol 2003, 19:538-543.

28. Frearson $\mathrm{JA}$, Wyatt $\mathrm{PG}$, Gilbert IH, Fairlamb AH: Target assessment for antiparasitic drug discovery. Trends Parasitol 2007, 23:589-595.

29. Feng X, Rodriguez-Contreras D, Buffalo C, Bouwer HG, Kruvand E, Beverley SM, Landfear SM: Amplification of an alternate transporter gene suppresses the avirulent phenotype of glucose transporter null mutants in Leishmania mexicana. Mol Microbiol 2009, 71:369-381.

30. Joet T, Eckstein-Ludwig U, Morin C, Krishna S: Validation of the hexose transporter of Plasmodium falciparum as a novel drug target. Proc Natl Acad Sci USA 2003, 100:7476-7479.

31. Saliba K, Krishna S, Kirk K: Inhibition of hexose transport and abrogation of $\mathrm{pH}$ homeostasis in the intraerythrocytic malaria parasite by an 0-3hexose derivative. FEBS Lett 2004, 570:93-96.

32. Joet T, Chotivanich K, Silamut K, Patel AP, Morin C, Krishna S: Analysis of Plasmodium vivax hexose transporters and effects of a parasitocidal inhibitor. Biochem J 2004, 381:905-909.

33. Fayolle M, lonita M, Krishna S, Morin C, Patel AP: Probing structure/affinity relationships for the Plasmodium falciparum hexose transporter with glucose derivatives. Bioorg Med Chem Lett 2006, 16:1267-1271.

34. Ionita M, Krishna S, Leo PM, Morin C, Patel AP: Interaction of O-(undec-10en)-yl-D-glucose derivatives with the Plasmodium falciparum hexose transporter (PfHT). Bioorg Med Chem Lett 2007, 17:4934-4937.

35. Slavic K, Derbyshire ET, Naftalin RJ, Krishna S, Staines HM: Comparison of effects of green tea catechins on apicomplexan hexose transporters and mammalian orthologues. Mol Biochem Parasitol 2009, 168:113-116.

36. Naftalin RJ, Afzal I, Cunningham P, Halai M, Ross C, Salleh N, Milligan SR: Interactions of androgens, green tea catechins and the antiandrogen flutamide with the external glucose-binding site of the human erythrocyte glucose transporter GLUT1. Br J Pharmacol 2003, 140:487-499.

37. Sannella AR, Messori L, Casini A, Francesco Vincieri F, Bilia AR, Majori G, Severini C: Antimalarial properties of green tea. Biochem Biophys Res Commun 2007, 353:177-181.

38. Dorin-Semblat D, Quashie N, Halbert J, Sicard A, Doerig C, Peat E, RanfordCartwright L, Doerig C: Functional characterization of both MAP kinases of the human malaria parasite Plasmodium falciparum by reverse genetics. Mol Microbiol 2007, 65:1170-1180.

39. Slavic K, Straschil U, Reininger L, Doerig C, Morin C, Tewari R, Krishna S: Life cycle studies of the hexose transporter of Plasmodium species and genetic validation of their essentiality. Mol Microbiol 2010, 75:1402-1413.

40. Blume M, Hliscs M, Rodriquez-Contreras D, Sanchez M, Landfear S, Lucius R, Matuschewski K, Gupta N: A constitutive pan-hexose permease for the Plasmodium life cycle and transgenic models for screening of antimalarial sugar analogs. FASEB J 2011, 25:1218-1229.

41. Slavic K, Delves MJ, Prudencio M, Talman AM, Straschil U, Derbyshire ET, Xu Z, Sinden RE, Mota MM, Morin C, Tewari R, Krishna S, Staines HM: Use of a selective inhibitor to define the chemotherapeutic potential of the plasmodial hexose transporter in different stages of the parasite's life cycle. Antimicrob Agents Chemother 2011, 55:2824-2830.

42. Florens $L$, Washburn MP, Raine JD, Anthony RM, Grainger M, Haynes JD, Moch JK, Muster N, Sacci JB, Tabb DL, Witney AA, Wolters D, Wu Y, Gardner MJ, Holder AA, Sinden RE, Yates JR, Carucci DJ: A proteomic view of the Plasmodium falciparum life cycle. Nature 2002, 419:520-526. 
43. Hall N, Karras M, Raine JD, Carlton JM, Kooij TW, Berriman M, Florens L, Janssen CS, Pain A, Christophides GK, James K, Rutherford K, Harris B, Harris D, Churcher C, Quail MA, Ormond D, Doggett J, Trueman HE, Mendoza J, Bidwell SL, Rajandream MA, Carucci DJ, Yates JR, Kafatos FC, Janse CJ, Barrell B, Turner CM, Waters AP, Sinden RE: A comprehensive survey of the Plasmodium life cycle by genomic, transcriptomic, and proteomic analyses. Science 2005, 307:82-86.

44. Lasonder E, Ishihama Y, Andersen JS, Vermunt AM, Pain A, Sauerwein RW, Eling WM, Hall N, Waters AP, Stunnenberg HG, Mann M: Analysis of the Plasmodium falciparum proteome by high-accuracy mass spectrometry. Nature 2002, 419:537-542.

45. Lasonder E, Janse CJ, van Gemert GJ, Mair GR, Vermunt AM, Douradinha BG, van Noort V, Huynen MA, Luty AJ, Kroeze H, Khan SM, Sauerwein RW, Waters AP, Mann M, Stunnenberg HG: Proteomic profiling of Plasmodium sporozoite maturation identifies new proteins essential for parasite development and infectivity. PLoS Pathog 2008, 4:e1000195.

46. Tarun AS, Peng X, Dumpit RF, Ogata Y, Silva-Rivera H, Camargo N, Daly TM, Bergman LW, Kappe SH: A combined transcriptome and proteome survey of malaria parasite liver stages. Proc Nat Acad Sci USA 2008, 105:305-310.

47. White NJ: The role of anti-malarial drugs in eliminating malaria. Malar J 2008, 7(Suppl 1):S8.

48. Beutler E, Duparc S: Glucose-6-phosphate dehydrogenase deficiency and antimalarial drug development. Am J Trop Med Hyg 2007, 77:779-789.

49. Prudencio M, Rodriguez A, Mota MM: The silent path to thousands of merozoites: the Plasmodium liver stage. Nat Rev Microbiol 2006, 4:849-856.

50. Feistel T, Hodson CA, Peyton DH, Landfear SM: An expression system to screen for inhibitors of parasite glucose transporters. Mol Biochem Parasitol 2008, 162:71-76.

51. Rodriguez-Contreras D, Feng X, Keeney KM, Bouwer HG, Landfear SM: Phenotypic characterization of a glucose transporter null mutant in Leishmania mexicana. Mol Biochem Parasitol 2007, 153:9-18.

52. Gamo FJ, Sanz LM, Vidal J, de Cozar C, Alvarez E, Lavandera JL, Vanderwall DE, Green DV, Kumar V, Hasan S, Brown JR, Peishoff CE, Cardon LR, Garcia-Bustos JF: Thousands of chemical starting points for antimalarial lead identification. Nature 2010, 465:305-310.

53. Guiguemde WA, Shelat AA, Bouck D, Duffy S, Crowther GJ, Davis PH, Smithson DC, Connelly M, Clark J, Zhu F, Jimenez-Diaz MB, Martinez MS, Wilson EB, Tripathi AK, Gut J, Sharlow ER, Bathurst I, El Mazouni F. Fowble JW, Forquer I, McGinley PL, Castro S, Angulo-Barturen I, Ferrer S, Rosenthal PJ, Derisi JL, Sullivan DJ, Lazo JS, Roos DS, Riscoe MK, Phillips MA, Rathod PK, Van Voorhis WC, Avery VM, Guy RK: Chemical genetics of Plasmodium falciparum. Nature 2010, 465:311-315.

54. Verlinde CL, Hannaert V, Blonski C, Willson M, Perie JJ, Fothergill-Gilmore LA, Opperdoes FR, Gelb MH, Hol WG, Michels PA: Glycolysis as a target for the design of new anti-trypanosome drugs. Drug Resist Updat 2001, 4:50-65.

55. Azema L, Claustre S, Alric I, Blonski C, Willson M, Perie J, Baltz T, Tetaud E, Bringaud F, Cottem D, Opperdoes FR, Barrett MP: Interaction of substituted hexose analogues with the Trypanosoma brucei hexose transporter. Biochem Pharmacol 2004, 67:459-467.

56. Burchmore RJ, Rodriguez-Contreras D, McBride K, Merkel P, Barrett MP, Modi G, Sacks D, Landfear SM: Genetic characterization of glucose transporter function in Leishmania mexicana. Proc Natl Acad Sci USA 2003, 100:3901-3906.

57. Burchmore RJ, Landfear SM: Differential regulation of multiple glucose transporter genes in Leishmania mexicana. J Biol Chem 1998, 273:29118-29126.

58. Derbyshire ET, Franssen FJ, de Vries E, Morin C, Woodrow CJ, Krishna S, Staines HM: Identification, expression and characterisation of a Babesia bovis hexose transporter. Mol Biochem Parasitol 2008, 161:124-129.

59. Blume M, Rodriguez-Contreras D, Landfear S, Fleige T, Soldati-Favre D, Lucius R, Gupta N: Host-derived glucose and its transporter in the obligate intracellular pathogen Toxoplasma gondii are dispensable by glutaminolysis. Proc Natl Acad Sci USA 2009, 106:12998-13003.

60. Ebikeme CE, Peacock L, Coustou V, Riviere L, Bringaud F, Gibson WC, Barrett MP: N-acetyl D-glucosamine stimulates growth in procyclic forms of Trypanosoma brucei by inducing a metabolic shift. Parasitology 2008, 135:585-594

61. Naula CM, Logan FJ, Wong PE, Barrett MP, Burchmore RJ: A glucose transporter can mediate ribose uptake: definition of residues that confer substrate specificity in a sugar transporter. J Biol Chem 2010, 285:29721-29728.
62. Kirk K, Horner HA, Elford BC, Ellory JC, Newbold Cl: Transport of diverse substrates into malaria-infected erythrocytes via a pathway showing functional characteristics of a chloride channel. J Biol Chem 1994, 269:3339-3347.

63. Joet T, Holterman L, Stedman TT, Kocken CH, Van Der Wel A, Thomas AW, Krishna S: Comparative characterization of hexose transporters of Plasmodium knowlesi, Plasmodium yoelii and Toxoplasma gondii highlights functional differences within the apicomplexan family. Biochem J 2002, 368:923-929.

64. Bakker BM, Walsh MC, ter Kuile BH, Mensonides Fl, Michels PA, Opperdoes FR, Westerhoff HV: Contribution of glucose transport to the control of the glycolytic flux in Trypanosoma brucei. Proc Natl Acad Sci USA 1999, 96:10098-10103.

65. Barrett MP, Tetaud E, Seyfang A, Bringaud F, Baltz T: Trypanosome glucose transporters. Mol Biochem Parasitol 1998, 91:195-205.

66. Tetaud E, Barrett MP, Bringaud F, Baltz T: Kinetoplastid glucose transporters. Biochem J 1997, 325(Pt 3):569-580.

67. Waitumbi JN, Tetaud E, Baltz T: Glucose uptake in Trypanosoma vivax and molecular characterization of its transporter gene. Eur J Biochem 1996, 237:234-239.

68. Corpe CP, Bovelander FJ, Munoz CM, Hoekstra JH, Simpson IA, Kwon O, Levine M, Burant CF: Cloning and functional characterization of the mouse fructose transporter, GLUT5. Biochim Biophys Acta 2002, 1576:191-197.

\section{doi:10.1186/1475-2875-10-165}

Cite this article as: Slavic et al.: Plasmodial sugar transporters as antimalarial drug targets and comparisons with other protozoa. Malaria Journal 2011 10:165.

\section{Submit your next manuscript to BioMed Central and take full advantage of:}

- Convenient online submission

- Thorough peer review

- No space constraints or color figure charges

- Immediate publication on acceptance

- Inclusion in PubMed, CAS, Scopus and Google Scholar

- Research which is freely available for redistribution

Submit your manuscript at www.biomedcentral.com/submit
C) Biomed Central 